\title{
SEÑALES DE NUESTRO TIEMPO
}

Alba Nubia Rodríguez Pizarro 


\title{
RESUMEN
}

\begin{abstract}
En el artículo se identifican algunos procesos globales como señales de una profunda transformación social: la revolución tecnológica expresada en nuevos sistemas de información y comunicación, el final de la guerra fría, la emergencia de nuevos movimientos sociales, la reestructuración del capitalismo, la unificación europea, constantes movimientos de personas de un lugar a otro, en busca de seguridad, refugio o mejores condiciones de vida, entre otras, y frente a las cuales no hay un acuerdo interpretativo de los procesos de cambio social que vivimos, solo sabemos que estamos frente a un gran proceso de cambio, que unos ubican como una continuidad de la modernidad y otros marcan como el producto de una discontinuidad entre una etapa y otra. Indudablemente esto plantea nuevos desafíos en la formación y en la acción profesional.
\end{abstract}

$\square$ n la actualidad no sólo asistimos a un cambio de siglo y de milenio, sino a procesos que son señales de una profunda transformación social. La revolución tecnológica expresada en nuevos sistemas de información y comunicación, el final de la guerra fría, la ejecución de guerras preventivas, la emergencia de nuevos movimientos sociales, la reestructuración del capitalismo, la unificación Europea, constantes movimientos de personas, que van de un lugar a otro, en busca de seguridad, refugio o mejores condiciones para la realización de la vida, son entre otras, señales de nuestro tiempo, que dan cuenta de un cambio social importante y que algunos analistas denominan como el fin de la modernidad y el paso a la postmodernidad (Lyotard, Harvey, Bauman, Haraway) o para quienes no aceptan las características y el paradigma propuesto por los postulados postmodernos, estaríamos en una modernidad tardía (Giddens), lo cual implica una continuidad y no el final del horizonte moderno. Con todo esto lo que se discute es la definición de la sociedad actual.

Desde diversos análisis, la sociedad vigente se define como "la sociedad del riesgo" en términos de Ulrich, Beck (1998) ${ }^{1}$, "la sociedad desestructurada" nos dice Alain Touraine

${ }^{1}$ Ulrich Beck plantea: «A medida que se desvanece el mundo bipolar, pasamos de un mundo de enemigos a un mundo de peligros y riesgos. ¿pero que quiere decir riesgo? Riesgo es el enfoque moderno de la previsión y control de las consecuencias futuras de la acción humana, las diversas consecuencias no deseadas de la modernización radicalizada. Es un intento (institucionalizado) de colonizar el futuro, un mapa cognitivo. Toda sociedad, por su puesto, ha experimentado peligros.. 
(2001), y "la sociedad red" plantea Manuel Castell (2001), para nombrar algunas de las discusiones contemporáneas acerca del postmodernismo, la sociedad postindustrial y la globalización del sistema mundial ${ }^{2}$. Con estos debates y corrientes teóricas lo que se intenta es definir la sociedad contemporánea. Según Melucci(2001), detrás de todos estas controversias lo que se esconde es la imposibilidad de explicar de qué sociedad estamos hablando. De acuerdo con esta imposibilidad, otra señal de nuestro tiempo está representada en no saber en qué tipo de sociedad estamos y hacia donde vamos. En la modernidad "era claro" que caminábamos hacia el progreso, al mejoramiento, al desarrollo tecnológico, etc. Hoy nos encontramos con una sociedad "amenazada por los efectos no intencionales de la acción humana”. Se reconoce que los seres humanos han sido agentes de su acción pero también pacientes de la misma. El futuro se presenta como amenaza y no como un refugio de promisión. La incertidumbre caracteriza el mundo de la vida, y es alimentada por no saber hacia donde caminamos (Beck, 2002:5).

Frente a todas estas señales, no hay un acuerdo interpretativo de los procesos de cambio social que vivimos, solo sabemos que estamos frente a un gran proceso de cambio, que unos ubican como una continuidad de la modernidad y otros marcan como el producto de una discontinuidad entre una etapa y otra. ¿Cuáles serían las señales cualitativas que marcan la discontinuidad entre la modernidad y la modernidad tardía o la posmodernidad? A este interrogante Alberto Melucci responde: existen dos fenómenos que van a marcar esa discontinuidad, "el fenómeno nuclear y la intervención en la naturaleza interna” (Melucci, 2001: 30). Estos dos referentes constituyen de manera inequívoca el presente, son hechos sociales incomparables con todo lo sucedido anteriormente en las sociedades humanas y que afectan de manera total al mundo contemporáneo. El fenómeno nuclear es la amenaza de la destrucción total de la humanidad y la manipulación genética pone sobre la mesa que para el ser humano es poco lo que queda por fuera de su intervención y manipulación. A este nivel no es posible retroceder, "ya no es posible reducir a cero el conocimiento que se encuentra en la base de estos acontecimientos a menos que se imagine una catástrofe definitiva" (Idem: 31). Tampoco es posible negar que nos encontramos frente a una discontinuidad ${ }^{3}$. Son acontecimientos que concretan un antes y un después de manera bien delimitada.

Beck diferencia entre una primera y una segunda modernidad. La primera modernidad, se fundamenta en sociedades de estados-nación, donde las relaciones y redes sociales se

Pero el régimen del riesgo es una función de un orden nuevo: no es nacional, sino global». Véase Beck, Ulrich (2002), La sociedad del riesgo global. Editorial siglo XXI. Madrid. Pág. 5.

${ }^{2}$ Sobre estos debates, ver en Cuadernos de la Fundación M. Botín, Teorías para una nueva sociedad, Manuel Castells, Anthony Giddens y Alan Touraine (2001). Observatorio de análisis de tendencias. Madrid.

${ }^{3}$ Con base en estos planteamientos queremos expresar que compartimos la idea de discontinuidad, más no que nos ubicamos en ninguno de los paradigmas propuestos para expresar y explicar la sociedad existente. 
entienden en sentido territorial, caracterizándose además por el pleno empleo, el desarrollo industrial, la explotación y dominio de la naturaleza. Esta primera modernidad ha quedado debilitada por cinco procesos inter.-relacionados: la globalización, la individualización, la revolución de los géneros, el sub-empleo y los riesgos globales, procesos que son consecuencias imprevistas del éxito del capitalismo ${ }^{4}$. La segunda modernidad debe responder a todos estos retos (Beck, 2002:2-4). Este planteamiento también reconoce una discontinuidad y plantea el surgimiento de un nuevo tipo de orden global, un nuevo tipo de sociedad y una nueva vida personal.

En ese sentido y en términos de Anthony Giddens, hoy lo que se pone en cuestión es el precepto "cuanto más sepamos de nosotros mismos y cuanto más sepamos del mundo de la naturaleza, mejor podremos controlar nuestra historia, forjar nuestro destino y regular lo que hacemos para nuestros propios fines". En el mundo actual el mayor logro del ser humano ha sido conocer e intervenir el mundo de la naturaleza y llegar a un desarrollo tecnológico que en vez de permitirle ser "dueño" de su destino, lo ha llevado a construir un mundo que es incapaz de controlar. "Este no es un mundo donde los seres humanos dominemos nuestra historia"(Giddens, 2002:71), todo lo contrario, el desarrollo y el profundo conocimiento han conducido al mundo en condición de incertidumbre, dados los efectos de la tecnología y de la manipulación de la naturaleza. Hoy son incalculables las consecuencias de la acción humana. Tanto los significativos desarrollos tecnológicos, como la imposibilidad de control del mundo creado por el ser humano tiene profundas repercusiones en la sociedad y en los sujetos que conforman esa sociedad.

El interés de este escrito no es elaborar una amplia sustentación sobre el surgimiento de un nuevo tipo de sociedad. Compartimos que hoy se da una discontinuidad entre lo que se ha llamado modernidad y una nueva forma que emerge y que los acontecimientos que dan cuenta de esa discontinuidad afectan todo lo que hoy se denomina el sistema mundo. Las manifestaciones de ese cambio social, de la eclosión de un nuevo tipo de sociedad, son diferentes en los países del norte y en los países del sur ${ }^{5}$ y su repercusión se da tanto en las estructuras sociales como en las vidas personales.

Me detendré en algunas de las manifestaciones de esa nueva sociedad para los países del sur, que considero constituyen el punto de partida para desarrollar algunas reflexiones en torno a dos ejes, el primero que las realidades que surgen en el sistema mundo como

${ }^{4}$ Para Marx el capitalismo se destruiría por engendrar sus propias contradicciones, para Beck los mayores problemas del capitalismo se dan con base en su éxito en su total expansión.

${ }^{5}$ No hablamos de países centrales y periféricos, por que son términos considerados inadecuados para dar cuenta del sistema mundo que se impone, esto no quiere decir que desconozcamos las relaciones de dominación, sino que a lo que queremos atender es que a pesar de que se impone un sistema mundial y que por lo tanto el centro es difuso, es necesario seguir estableciendo la diferenciación entre países que aunque atravesados por los mismos procesos no comparten las mismas consecuencias dados los procesos, momentos históricos y relaciones de poder que se establecen entre unos y otros (los del norte y los del sur). 
consecuencia del proceso de transformación social para los países del sur como para los países del norte, marcan nuevos espacios y demandan nuevas y creativas formas de intervención social y nos evidencian la necesidad de tener en cuenta otros aspectos en la formación y en el ejercicio de los y las trabajadoras (es) sociales (para referirme a una disciplina social concreta). Los trazos que hago en este escrito son producto de algunas reflexiones en ningún momento acabadas, lo que pretenden es abrir un horizonte de debate.

\section{SOBRE NUEVOS CAMPOS Y FORMAS DE INTERVENCIÓN}

Algo que ha caracterizado a estos países y que afortunadamente continúa vigente es que son pueblos de sueños y de esperanzas, sin embargo, hoy comienza a invadir el vacío del sueño frente a un mundo que se ve abocado a su propia destrucción y donde los países del sur no han jugado en términos de decisiones, de presencia y de producción de un nuevo orden mundial (en condiciones de equidad). Son países que no han agotado una primera modernidad, no han resuelto el problema del reparto de la riqueza, no han solucionado el hambre ni la miseria pero hoy comparten y compiten en el mismo espacio y en el mismo tiempo y los retos que marca una segunda modernidad ${ }^{6}$ sin agotar la primera.

Los cinco factores establecidos por Beck y mencionados en el inicio de este escrito, como consecuencias no previstas del triunfo de la primera modernización se manifiestan de manera implacable en los países del sur, donde de ningún modo se consolidaron las características de la primera modernidad: como el pleno empleo, progreso, certidumbre, etc. Por esto hoy sentimos la agudización del desempleo, la pobreza, la pérdida de legitimidad del Estado, los elevados indices de violencia y crímen cotidianos. La gran paradoja se encuentra en que no decidimos, no construimos, no agotamos una primera modernidad ni siquiera asistimos como espectadores, pero si fuimos expropiados para el logro de la primera modernidad en los países del norte. Hoy sentimos los grandes efectos "no intencionales" del éxito de esa modernidad. Con este planteamiento no quiero negar las contradicciones internas de nuestros países, en lo que quiero enfatizar es en la agudización de esas contradicciones como producto de factores macro-estructurales que no podemos desconocer al analizar e intervenir nuestras realidades.

Muchos estudios y análisis han demostrado que la globalización de la economía, entendida "como el proceso a través del cual se expande el mercado y donde las fronteras nacionales parecen desaparecer en ese movimiento de expansión" es la continuación del proceso de internacionalización del capital, que se inició con la extensión del comercio de mercancías y servicios, y pasó por la expansión de los créditos financieros y generalizó el

${ }^{6}$ Estoy utilizando los términos de Ulrich Beck de modernidad y modernidad tardía o segunda modernidad. 
desplazamiento del capital industrial a través de multinacionales.(Del castillo, 2002:101). Giddens (2002) nos diría que la globalización no es solo económica, es también política y cultural y además establece un amplio debate sobre las consecuencias de la globalización en países en vía de desarrollo, concluyendo que los procesos de globalización no son la "única causa" que ha llevado a estos países a la enorme pobreza en que viven hoy sus habitantes. Pero a su vez reconoce que la globalización no cumplió su cometido en los países de desarrollo: disminuir y redistribuir la pobreza. Compartimos esta premisa, y adicionamos, que los procesos de globalización han contribuido al aumento del desempleo, la pobreza, la violencia, en síntesis, a las no condiciones para la realización de la vida. Sustentamos que han contribuido a la agudización de problemáticas ya existentes en la medida que no es posible que los países no hegemónicos se integren a una economía global, mientras que los países hegemónicos sean farsantes con relación al libre comercio. Mientras predican libre comercio para los países pobres, no abren sus propias economías y la compra de productos a los países del sur, las condicionan a través de políticas de control de la migración. Los últimos planteamientos de la Unión Europea en referencia al intercambio comercial y a la cooperación para el desarrollo con los países del sur, la circunscribían como posible, en la medida que los gobiernos de los países no hegemónicos establecieran verdaderos compromisos para el control de los migrantes; si nuestros países no adquirían esta responsabilidad, o había incumplimiento, no habría ningún intercambio comercial y mucho menos cooperación para el desarrollo, lo cual, ratifica las relaciones de dominación y la subordinación entre los países del norte y los del sur.

La agudización de la pobreza ${ }^{7}$, la violencia, la falta de condiciones de subsistencia y para un proyecto de vida, son factores que inciden en que los países del sur se conviertan en grandes expulsores de población, en países "productores" de migrantes que llegan a

${ }^{7}$ En la última década la pobreza se ha agudizado en todas partes. La ONU afirma que más de 2.400 Millones de personas viven ahora sin saneamientos, un considerable aumento respecto a la década anterior; 1.200 millones carecen de agua potable segura; un número parecido carece de vivienda y servicios sanitarios y educativos adecuados; más de 1.500 millones sufren desnutrición, no porque falte comida o sobre sequía, sino por la creciente marginalización y exclusión de los pobres.

Las naciones más pobres gastan ahora más en pagar los intereses de su deuda a los países más ricos de lo que emplean en sanidad y educación en sus propios países. (Beck, 2002: 8).

Otro dato que vale la pena tener en cuenta con relación al aumento de la pobreza en el mundo es el aportado en la última cumbre mundial sobre la alimentación de la FAO realizada en Italia en Junio 12,13 del 2002: el hambre provoca 24.000 muertes al día. Unas víctimas que se podrían evitar fácilmente, como señaló un delegado Africano: sólo con la comida que se desecha en los mercados italianos se podría alimentar 20 millones de personas al día, pero el mundo desarrollado esta más pendiente de sus 300 millones de obesos.

En los países del norte las manifestaciones comienzan a sentirse y a evidenciarse en el desmonte del Estado de Bienestar. Los periódicos: El País de España, Le Monde, de Francia, registran en primera página las significativas protestas de ciudadanos Franceses, Austriacos, Españoles quienes reclaman pensiones dignas, más y mejores servicios sociales y trato digno para los jubilados y prejubilados. Junio 3, 4,5 de 2003. 
distintos países del mundo, especialmente aquellos que hemos denominado países del norte. Los estudios especializados distinguen tres tipos de migrantes: i)el inmigrante que se desplaza en busca de trabajo. Entre estos hay dos categorías: unos que salen de su país de origen con su documentación en orden (estos son los "buenos inmigrantes") y otros que como consecuencia de las enormes dificultades en los tramites para obtener un permiso laboral y la falta de recursos económicos, educativos etc., no logran la documentación exigida y se convierten en ilegales -los "sin papeles"-; ii) los que salen de su país de origen por razones políticas -refugiados- iii); el tercer tipo, es difuso, porque son personas cuyo desplazamiento obedece a reagrupación familiar, por lo tanto en algunas ocasiones, son personas que ni siquiera han decidido migrar, como es el caso de muchos niños, jóvenes y personas mayores que salen de sus países de origen al encuentro de padres, hijos o hermanos.

La migración es una manifestación de los procesos de cambio social que se viven y es uno de los nuevos escenarios de intervención para el trabajo social. En los países de llegada se realizan diversas investigaciones, para determinar procedencia, forma de ingreso al país, necesidades, caracterización sociodemográfica. Los profesionales del trabajo social se ven abocados a intervenir en esta nueva situación. Su quehacer profesional va a estar atravesado por la incertidumbre; ya no se enfrentan a poblaciones socioculturalmente homogéneas, deben enfrentarse a la atención de personas portadoras de diversas culturas, diferentes idiomas, diversas cosmovisiones, a no ciudadanos, que por esta condición, no acceden a todas las formas de bienestar social establecidas por los Estados de llegada para sus ciudadanos, sin embargo, son seres humanos en "estado de necesidad", que es el objeto de intervención del trabajador social ${ }^{8}$. Hoy es uno de los mayores campos de trabajo para los trabajadores sociales europeos.

En los países emisores este es un campo que comienza a asomar como campo de intervención y que demanda a su vez nuevas formas de intervención. Es poco lo que se conoce sobre el impacto de los flujos migratorios en los países de salida, escasamente se tienen cifras sobre las personas que se movilizan. De acuerdo con algunas investigaciones realizadas en España, se conoce que de Ecuador y de Colombia desde inicio de la década 90 migran especialmente mujeres', la gran mayoría son madres y han dejado sus hijos al cuidado -en el mejor de los casos- de sus padres, o en su defecto en manos de abuelas o tías, o sino a cargo de vecinas. Esto es lo que refieren las mujeres al preguntarles por sus

\footnotetext{
${ }^{8}$ En las III Jornadas de Intervención Social en Castilla La Mancha, se planteo el ser humano en estado de necesidad como el «objeto» de intervención del trabajador social». Memorias publicadas en la revista Área Social No 3 de Marzo del 2003. Colegio Oficial de Diplomados en Trabajo Social de Castilla La Mancha

${ }^{9}$ De acuerdo con datos publicados en el periódico «20 Minutos Madrid» de Junio 5 de 2003, a España llegan más mujeres que hombres. La mayoría son latinoamericanos, ecuatorianos principalmente (140.000) seguidos de colombianos (75.000). Marruecos es el tercer país de procedencia, pero el que menos crece (50.000). La media de edad es de 25 a 39 años y vienen a trabajar en hostelería, construcción y servicio doméstico. En el mismo periódico también se plantea que hay una alta explotación laboral de los inmigrantes y la tasa de accidentes laborales es del 15\%.
} 
familias. Su esperanza es trabajar, ¿en qué? es lo menos importante, lo fundamental es cada mes poder enviar una suma de dinero que garantice la manutención de la familia, no se habla de bienestar porque para este se necesitan otros componentes adicionales al económico, los afectos, la presencia del otro que ya no está. El sueño que sigue a encontrar un trabajo es "traer" a sus hijos, pero mientras esto sucede, las familias se recomponen, surgen diversos lazos y diferentes medios para hacer presencia. Si no se sabía se aprende a manejar "el internet", así tan sólo escasamente se lea y escriba, se establece comunicación cotidiana, hay presencialidad a través de lo que caracteriza la modernidad tardía, el desarrollo informático, se es madre o padre vía Internet o vía telefónica, es a través de estos medios que se "interactúa", se da el ejercicio de la autoridad, se expresan afectos y se transmiten presencias. Encontramos la modernidad tardía atravesando espacios que antes creíamos no podían ser invadidos.

Hoy, en los países de salida son muchas las familias monoparentales a raíz de la inmigración. Los sueños, las esperanzas de los que se van y de los que se quedan cambian. Los sueños son reemplazados por la incertidumbre que caracteriza la modernidad tardía. El campo de los duelos se amplía, además de los duelos por muerte se dan duelos por otra forma de ausencia que es la migración, se funda un no saber cuando nos volveremos a ver, cuando volveremos a encontrarnos, pero a su vez si le va bien estaremos todos mejor y tal vez en un tiempo (que es incalculable) nos volveremos a ver. Esto genera un profundo vacío una gran incertidumbre y ubica "seres humanos en estado de necesidad", que demandan la intervención del trabajador social, tanto en el espacio investigativo, para proporcionar conocimiento sobre una realidad como en la intervención. Intervención que ya no se hace con base en parámetros de seguridad sino donde lo que juega es la incertidumbre desde los dos lados, tanto de quiénes intervienen como de quienes son intervenidos.

Fenómenos como las migraciones se viven de manera diferente en los países de salida y los países de llegada, sin embargo son las dos caras de una misma moneda y han llevado a que los profesionales de las disciplinas sociales tengan que replantear las certidumbres de su aprendizaje y ya no actúen bajo las seguridades que deja la formación, sino sobre las incertidumbres que marca la sociedad y los destinos de las personas. Hoy ya no se interviene con base en lo que conocemos sino con base en lo que desconocemos. Se atiende a lo local pero no es posible desconocer lo global. Son formas interdependientes. Si hoy conocemos sobre las migraciones en los países de llegada y se interviene en estas es fundamental conocer e intervenir en los países de salida.

Otro campo al que quiero referirme está también asociado con las respuestas que se construyen a la agudización de los problemas de los países del sur y que comienzan a manifestarse en los países del norte ${ }^{10}$. Este campo sería el de las "nuevas formas políticas"

${ }^{10}$ Ulrich Beck al respecto plantea: «Invirtiendo el dictamen de Marx, podríamos decir con Shalini Randeria que muchas partes del «tercer mundo» muestran hoy a Europa la imagen de su 
las cuales en términos de Beck se refieren a la politica al margen y más allá de las instituciones representativas del sistema politico de los estados-nación. Centra la atención en los signos de una autoorganización (en última instancia global) de la politica que tiende a poner en movimiento todas las áreas de la sociedad. La subpolítica quiere decir política directa, es decir, la participación individual en las decisiones políticas, sorteando las instituciones de la formación representativa de la opinión (partidos políticos, parlamentos) y muchas veces en carencia incluso de protección jurídica. En otras palabras, subpolitica quiere decir configurar la sociedad desde abajo. (Beck, 2002: 61).

Surgen "nuevas formas" políticas tanto en el norte como en el sur que tienen el propósito de responder a los desafíos que marca el "momento bisagra" (Melucci, 2002), por el que atraviesa la sociedad en que vivimos y que afectan a todo el planeta y a todos los seres humanos que en él habitamos, llevan a construir formas de organización colectiva que permitan enfrentar los desafíos que marcan los retos del presente.

Hay diversas acciones colectivas que trascienden los ámbitos locales y nacionales hasta llegar a lo global. Las reivindicaciones que portan estas acciones, si bien es cierto se fundamentan en escenarios locales, sus demandas trascienden, no sólo se circunscriben a los espacios inmediatos, sino que establecen contactos y alianzas con actores políticos globales que "hacen política" al margen de las instituciones, ejemplos de estos movimientos son: el movimiento ecologista, el movimiento feminista, el movimiento pacifista. La gran novedad de estas acciones es su carácter de demanda global y no solamente nacional, trascienden las fronteras para establecer alianzas con otros actores, en ocasiones diferentes en términos culturales, lo cual implica diversidad de cosmovisión pero unidos a través de reivindicaciones comunes. Su lucha es por problemas de carácter global.

Las acciones colectivas no son un fenómeno nuevo en los países del sur. Las personas frecuentemente construyen un "nosotros" para protestar contra las injusticias, para demandar derechos sociales, económicos o políticos, para pedir reformas y cumplimiento de la política social, también para demandar seguridad del Estado, entre muchas otras

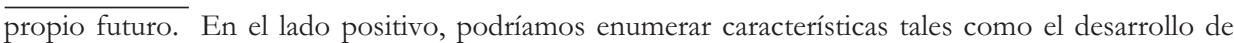
sociedades multirreligiosas, multiétnicas y multiculturales, los modelos interculturales y la tolerancia de la diferencia cultural, el pluralismo legal observable en diversos niveles y la multiplicación de las soberanías. En el aspecto negativo, podríamos señalar la extensión del sector informal de la economía y la flexibilización del trabajo, la desregulación legal de grandes sectores de la economía y de las relaciones laborales, la pérdida de legitimidad del estado, el crecimiento del desempleo y el subempleo, la intervención más enérgica de las corporaciones multinacionales y los elevados índices de violencia y crimen cotidianos. Todos estos aspectos, junto con los interrogantes y debates relacionados, implican que la sociedad del riesgo global en la que vivimos requiera un nuevo marco de referencia para poder entender la dinámica y las contradicciones de la segunda modernidad». (Beck, 2002: 4). La diferencia entre los países del norte y los del sur radica en que en los del norte las manifestaciones se están dando y en los del sur se han agudizado problemas heredados de la industrialización y no resueltos. 
motivaciones. Son manifestaciones que están presentes en la cotidianidad de nuestros países y han sido acciones que en muchas circunstancias nacen al margen de la política institucional y trascienden formas tradicionales de hacer política y de participar.

Las personas no sólo se han organizado para protestar y demandar por distintos motivos. Las mujeres han conformado acciones colectivas, como ollas comunitarias, que no sólo permiten solventar algunas carencias, sino a la vez constituir formas de organización política para la participación (y logran incluso convocar solidaridad de los hombres.). Son acciones que nacen como respuesta a necesidades que pueden calificarse de inmediatas (o coyunturales), pero que se van conformando en formas políticas, que además de intentar mejorar las condiciones de precariedad se van constituyendo en actores políticos, que trascienden el espacio privado y el ámbito nacional para establecer contacto con otras organizaciones de mujeres, hasta constituir redes de trabajo internacional en pro de la realización de derechos humanos. Son organizaciones que no se circunscriben al espacio nacional, sino que van hasta el ámbito internacional, haciendo de su problemática y de sus reivindicaciones factores que traspasan las fronteras del Estado-nación -como ya se dijo-. Un ejemplo de este tipo de acción se ha visto muy claramente expresado en los múltiples movimientos de mujeres latinoamericanas que llegaron hasta el Foro Social Mundial 2002 realizado en Porto Alegre, Brasil para manifestar que "otro mundo es posible". En Porto Alegre estuvieron representados 5000 millones de personas de los 6000 millones con los que cuenta el planeta (Ramonet, 2002: 57-58).

Estas formas organizativas rompen con formas tradicionales en dos sentidos: el primero, porque su organización no proviene, ni tiene vínculos con partidos políticos tradicionales. Los movimientos han evitado conscientemente hacer conexión con la política tradicional, en parte por la debilidad de la tradición política y también porque las formas políticas tradicionales son esferas especialmente construidas y habitadas por hombres y donde aún las mujeres continúan librando duras batallas para su conquista y no han logrado su reconocimiento. En segundo lugar, son acciones que a pesar de la "precariedad" en la que surgen logran llegar a espacios internacionales, donde ya las demandas no son de carácter local sino global. Haciendo conciencia que los problemas que afectan a la sociedad ya no solo se circunscriben a espacios inmediatos sino que el telón de fondo es la sociedad global.

Así, con relación a lo que Beck denomina la revolución de los géneros, estas acciones colectivas van a marcar hitos importantes en este sentido. A través de este tipo de organizaciones se logra una colectivización de los roles tradicionales de género como el cuidado del hogar, el cuidado de los niños. La colectivización de las tareas del hogar, se están transformando los roles de las mujeres aunque no están siendo tomados como retos concientes de la subordinación de género, si bien, estas mujeres no se han quejado de sus roles domésticos los usan como base para tener fuerza y legitimidad en sus demandas al 
Estado y para establecer redes no solo de carácter nacional sino internacional que se constituyen en embriones de sujetos globales. A la hora de mover sus preocupaciones hacia el área pública ellas están redefiniendo el significado con lo doméstico para incluir la participación y la lucha en vez de la obediencia y la pasividad. Los intereses de género se han colectivizado y politizado lo que ha permitido brindar una mayor conciencia de la subordinación de género y de las transformaciones prácticas en estratégicas o en estratégicos intereses de género.

Pero todo no queda en formas organizativas que trascienden la esfera privada y la politizan. Hoy se dan cita movimientos sociales cuya base principal está constituida por mujeres que hacen reivindicaciones de carácter global, los movimientos por la paz y la realización de derechos humanos, en este sentido nos encontramos con organizaciones tales como mujeres de negro, que aunque teniendo su origen en países del norte han logrado constituirse en un movimiento global con participación de mujeres del norte y del sur, sus demandas ya no son de carácter eminentemente local, articulan intereses locales y nacionales con intereses globales y sus reivindicaciones se legitiman desde roles tradicionales de género: "no pariremos más hijos para la guerra".

En este punto, nos podemos preguntar ¿son únicamente las mujeres las que están promoviendo nuevas formas políticas, al margen de la política tradicional que trascienden lo local y nacional para llegar a lo global? La respuesta es no. Solamente hemos iniciado por este tipo de acciones colectivas, pero surgen otras tan importantes como las mencionadas que van a estar alimentadas por hombres y mujeres, entre ellas los movimientos ecologistas que también trascienden demandas nacionales para instalarse en reivindicaciones globales al margen de la política tradicional. Sus demandas se basan en problemas globales. El problema medioambiental es global, como el logro de la paz. No podemos dejar de lado las organizaciones y acciones colectivas de comunidades indígenas tales como las de los Uwas en Colombia o los Kayapo ${ }^{11}$ en el Brasil que han conformado estructuras organizativas sólidas en pro de la conservación cultural y del medio ambiente hasta llegar a ámbitos internacionales donde hoy se plantea la pregunta si estamos frente al nacimiento de un movimiento cosmopolita?

\footnotetext{
${ }^{11}$ Los Kayapo en el Brasil, han constituido un movimientos ecologista muy fuerte en defensa no sólo de su cultura, sino de los posibles daños medioambientales que surgen a raíz de la construcción de represas para producción de energía. Para profundizar en el tema ver a Turner, Terence (2002). La cultura como base de la construcción identitaria en los movimientos indígenas contemporáneos: ¿una política auténtica de la inautenticidad? Ponencia del congreso Culturas en Contacto, Encuentros y desencuentros. Mayo 2002. Madrid.

El movimiento UWA, fue un movimiento que se gesto por la defensa del territorio del pueblo indígena UWA, su cultura y los recursos naturales del país. Constituyéndose en un movimiento de gran repercusión nacional e internacional, que hoy hace parte de los movimientos internacionales en defensa de los recursos naturales y el medio ambiente y el movimiento indigenista que algunos analistas lo ubican como uno de los movimientos cosmopolitas.
} 
Con estos ejemplos de distintas acciones colectivas que comienzan a vislumbrarse en nuestros países, como "nuevas formas políticas" que trascienden lo local y nacional, para establecer vínculos económicos, políticos y culturales con otras regiones del mundo, que establecen una adscripción colectiva ideológica a corrientes globales de pensamiento / acción, no quiero desconocer que aún no se traducen en una dinámica intensa que nos lleve a reconocerlas como movimientos sociales, por esto no utilizamos el concepto de movimiento social, sino de acciones colectivas que aun no alcanzan las formas organizativas que implica un movimiento social.

El punto que queremos destacar es que el campo incipiente de estas nuevas formas políticas a nuestro parecer también se configuran en un campo de conocimiento e intervención para el trabajo social; esta premisa la sustento, desde pensar que el ámbito de los procesos organizativos hace parte del objeto del trabajo social y más en el contexto en que estamos y estas formas de organización no son sólo esto sino que implican procesos sociales que traspasan fronteras. No es posible conocer e intervenir lo local sin tener como telón de fondo el momento histórico en que nos encontramos, lo cual constituiría lo nuevo en la intervención, esta debe mirar hacia la problemática global, hacia la forma social que surge en el sistema mundo y las formas organizativas y demandas que están teniendo como fondo el tipo de sociedad en que estamos.

La importancia de las acciones colectivas, no sólo está en que hoy dan cuenta también de problemas globales, lo que es verdaderamente fundamental está en que ya las acciones no podemos interpretarlas como producto de una crisis, como producto de una fase social que esta en su etapa terminal. El valor, de acuerdo con Melucci (2001: 16-20) es que son expresiones de un conflicto, son signos que anuncian un profundo cambio en la lógica y el funcionamiento de sociedades complejas. Son laboratorios para quienes nos ocupamos de la relación entre el actor y el sistema, entre individuo y colectivo, entre la identidad individual e identidad colectiva.

Las acciones colectivas que hemos descrito (que son sólo un ejemplo entre muchos otros) ya no coinciden ni con las formas tradicionales de organización de la solidaridad ni tampoco con los canales establecidos de representación política. Nos llevan a revisar conceptos que han sido usados a lo largo del tiempo: Estado, sociedad civil, público y privado, individual y colectivo; grupos de opuestos que pierden solidez y marcan un hito para la transformación del universo conceptual. Nos llaman a descifrar los procesos a través de los cuales los actores sociales llegan a construir un nosotros, que no sólo se hace en el ámbito de lo local, lo nacional, sino que incluso trasciende al plano global. Esto implica que hay una definición interactiva y compartida del significado y los objetivos de la acción. Sí los trabajadores sociales se ocupan de procesos sociales es necesario descifrar cómo construimos un nosotros para la acción, no solo en lo local, nacional, sino en lo global, como también las formas en que interaccionan sujetos y sistemas. 


\section{DESAFÍOS EN LA FORMACIÓN DE NUEVOS PROFESIONALES}

Los múltiples cambios sociales, la complejidad de la sociedad en que vivimos y los desafíos que debemos encarar en las sociedades de los países del sur, que desde mi punto de vista, son dobles porque no solo nos enfrentamos a las dinámicas y amenazas globales a las cuales no podemos escapar por hacer parte del sistema mundo, sino que también debemos enfrentar los problemas no resueltos que cada vez se agudizan de manera más dramática, generando no solo exclusiones por el reparto de la riqueza, sino también desigualdades que asumen la forma de privación cultural, destrucción de culturas tradicionales, sustituidas sólo por la marginalidad o el consumo dependiente y por la imposición de estilos de vida que ya no permiten a las personas bases culturales para la autoidentificación.

El proceso en que vivimos nos presenta dos caras: por un lado estamos en una sociedad que cada vez presenta un impulso más fuerte a la autonomía de los individuos, son las personas las que deben formarse por sí mismas, con mayor responsabilidad, disciplina, etc. "somos artífices y responsables de nuestra propia existencia". Para ilustrar, las instituciones educativas nos brindan un ejemplo muy acorde. El fracaso escolar es afrontado como un problema cada vez más de la persona y no de las instituciones y de las políticas educativas. En la familia se inicia un cambio de valores que contribuye de manera creciente a generar bases para la autonomía del sujeto y la extensión de los derechos personales En términos de Melucci, el individuo de esta sociedad compleja es una "potencialidad que se construye"(2002:32). La otra cara del proceso es que hay una fuerte tendencia a la masificación de los procesos sociales basados en la exclusión, la perdida de los rasgos distintivos que caracterizan a una persona, la manipulación de la información, el consumo estandarizado, el conformismo y la apatía.

Es en esta paradoja que nos movemos. Dado que los cambios sociales no son sólo en términos de las macro-estructuras sino en términos personales, el reto que hoy se nos presenta es que debemos develar en primer lugar la paradoja a la que como seres humanos estamos enfrentados en este contexto. En este sentido, pienso que es importante hacer conciencia del proceso, del cambio, de las rupturas, de los dobles desafíos que tenemos que afrontar. Por lo tanto, no podemos únicamente centrarnos en articular discursos científicos y técnicos brillantes, a estos hay que ser capaces de sumarles pasión y compromiso, para tender puentes entre la experiencia vital y las realidades sociales. Es necesario evidenciar la complejidad de la sociedad en que vivimos, por lo tanto el conocimiento y la intervención en esta realidad no es posible hacerla únicamente a partir de conocimiento y recursos formativos de base técnico científica, estos hay que complementarlos con una enorme creatividad, haciendo conciencia que lo que conocemos del mundo actual es poco y que por lo tanto no actuamos bajo certezas sino bajo incertidumbres. 
Con relación a la acción es importante pensar sobre los efectos no intencionales de la acción humana y en este sentido hay que tener en cuenta, no-solo los efectos no intencionales de las acciones de los actores sociales en general, sino también los efectos no intencionales de la acción de los Trabajadores sociales, este es un campo que permanece aun en el trastero de la reflexión.

Con la sistematización de experiencias, construimos conocimiento sobre la experiencia, hacemos visibles la construcción de sentido que hacen los actores y los profesionales de las diversas experiencias, pero hoy, cuando la realidad nos pone de manifiesto lo que ha sucedido: el mundo se ha puesto en riesgo a así mismo por el desarrollo tecnológico, la sociedad hoy se destruye así misma, pero también puede salvarse a sí misma, es fundamental reflexionar sobre la condición de agencia y paciencia. Somos constructores, artífices pero a la vez somos pasivos frente a los efectos de la acción. Esos efectos no los podemos controlar. Me parece que es importante comenzar a introducir en la formación de futuros profesionales la reflexión sobre los efectos de la acción, como una parte valiosa en la sistematización de experiencias e incluso como reflexión constante frente a todo proceso de intervención.

El mundo actual nos evidencia que el ser humano no solo ha sido artífice de su propia historia, sino que ha llegado el momento de no poder controlar su creación, el mundo no se ha "sometido" frente al ser humano, hoy se levanta y pone al descubierto la multiplicidad de riesgos a los que se enfrenta la humanidad. En síntesis, lo que deseo plantear es que en la formación de trabajadores sociales debemos hoy colocar sobre la mesa no sólo un hacer profesional sino una condición personal que esta atravesada por la multiplicidad de factores mencionados. En ese hacer profesional se juega la condición personal signada por la incertidumbre que se va a enfrentar a personas también atravesadas por la incertidumbre. No actuamos con base solamente en conocimientos técnicos y científicos, actuamos con base en el desconocimiento de lo que nos depara una sociedad profundamente compleja y sobre la base de no certezas, de sujetos múltiples diversos y móviles y finalmente de lo que depara la acción social que procuramos como profesionales.

Comparto algunas conclusiones de las III Jornadas de Intervención Social en CastillaLa Mancha, con relación a que es importante ideo-logizar la profesión, esto significa volver a creer que las cosas pueden ser diferentes, que es necesario para la intervención recuperar la utopía, en términos de Hugo Zemelman no como el sueño, sino como lo posible. Es conveniente tener en cuenta en primer lugar, que el Trabajo Social, como reflexión activa sobre nuestra sociedad también contiene el espejo íntimo donde se refleja la vocación de modificar la realidad sin escapar de ella, y mas aún siendo parte de esa realidad.

En la formación de los Trabajadores Sociales debemos caminar hacia trascender el tratamiento parcelario de realidades complejas. La exclusión social, el crecimiento de la 
dependencia asociado al envejecimiento de la población o el reto de la igualdad y la equidad son realidades complejas que exigen un tratamiento integral. No podemos quedarnos con enfoques sectoriales, parciales hoy el mundo nos exige una mirada integral. Lo macro-estructural incide y se refleja en lo cotidiano en lo individual en los "nucleamientos colectivos" (Zemelman 1.995: 29).

Hasta aquí mis reflexiones profesionales que han sido también, deliberadamente relato sobre la vida y sus infinitas posibilidades. Este escrito lo he hecho en busca de complicidades de compañeros de viaje con quienes emprender la aventura de descubrir día a día nuevos mundos, nuevos horizontes y no sólo de descubrirlos sino de conocerlos, comprenderlos y debatirlos. Aquí aparece el profundo dolor que genera intentar comprender un mundo que se revela a la posibilidad del conocimiento, pero también con la certeza que la realidad no es solo lo objetivo sino también lo que soñamos, lo que queremos, que es los que nos motiva a la acción.

\section{BIBLIOGRAFÍA}

Abin, Carlos y OTROS (2002). Porto Alegre (Foro Social Mundial 2002). Una asamblea de la humanidad. Icaria Más Madera. Barcelona

BECK, ULRICH (2001). La sociedad del Riesgo global. Siglo veintiuno Editores, Madrid

BECK, ULRICH (2000). The Cosmopolitan perspective: Sociologia of the second age of modernity, British Journal.

BECK, ULRICH (1999). Que es la globalización? Falacias del globalismo, respuestas a la globalización. Páidos Estado y Sociedad, Barcelona.

BECK, ULRICH (1998). La sociedad del Riesgo. Hacia una nueva modernidad. Paidos, Barcelona.

BECK, U., GIDDEns, A., y LASH, S. (1997). Modernización Reflexiva. Politica, tradición y estética en el orden social moderno. Alianza Universidad, Madrid

Castells, manuel y otros (2001). Teorías para una nueva sociedad. Cuadernos de la fundación M. Botin, Madrid.

COLOM MASFRET, DOLORS (2002). Revista de servicios sociales y politica Social $\mathrm{N}^{\circ} 58$.

DOUGLAS, MARY (1992). Risk and Blame. Emap in Cultural Theory, London

GIDDENS, A., BAUMAN, Z., LUHMAN N., BECK, U. (1996). Las consecuencias perversas de la modernidad. Antrhopos, Barcelona.

GIDDENS, A.,HUTTON WILL (2001). En el límite. La vida en el capitalismo global. Kriterios editores, Barcelona.

JONAS, HANS (2001). Más cerca del perverso fin y otros diálogos y ensayos. Los libros de la catarata, Madrid.

JONAS, HANS (1995). El Principio de responsabilidad. Editorial Hardes, Barcelona.

LEÓN, EMma y ZEMELMAN, HUGO (1997). Subjetividad: Umbrales del pensamiento social. Editorial Anthropos. Barcelona

MeluCCI, AlBerto (2002). Vivencia y convivencia. Editorial Trotta. Edición de Jesús Casquete. Madrid.

MARÍN DEL CASTILLO, MARÍA MERCEDES (2003). "Influencia de la globalización en los Servicios Sociales y el Trabajo Social en nuestra práctica profesional. Estrategias y Alternativas”, en Revista Área Social N³ de Marzo del 2003. Págs. 99-111

PAJARES, MIGUEL (1998). La inmigración en España. Retos y propuestas. Icaria Antrazyt, editorial S.A. Barcelona. 
SAFA, HELEN ICKEN (1990). "Women's Social Movements in Latin America", en Gender \& Society,

Vol.4, Issue 3, Special Issue: Women and Development in the third World. Septiembre 1990.

Pág. 354 - 369

Solé, CARlota (1998). Modernidad y Modernización. Antrhopos, Barcelona.

Zamanillo, t y Gaitán, L (1991). Para comprender el Trabajo Social. Editorial, Verbo Divino, Madrid. 